\title{
ANALISIS SIKAP MURID TERHADAP MATA PELAJARAN SAINS DI SEKOLAH JENIS KEBANGSAAN (TAMIL)
}

\author{
${ }^{1}$ Suppiah Nachiappan, ${ }^{2}$ Lata Muthaiah, ${ }^{3}$ Sandra Suffian \\ 1,2,3 Universiti Pendidikan Sultan Idris \\ 35900 Tanjong Malim, Perak
}

Received : 21 Oktober 2017; Accepted : 3 November 2017; Published : 15 December 2017

\begin{abstract}
Abstrak
Kajian ini adalah untuk menganalisis sikap murid dan cara-cara guru serta ibu bapa dapat membantu terhadap mata pelajaran Sains di Sekolah Jenis Kebangsaan (Tamil). Sampel kajian melibatkan sepuluh orang murid tahun lima di Sekolah Jenis Kebangsaan (Tamil) yang terletak di daerah Kinta Utara. Kaedah kajian ini menggunakan teks jawapan yang ditulis oleh responden sebagai data dan ditranskripsikan menjadi teks kajian. Teks kajian ini seterusnya dianalisis dengan menggunakan kaedah Hermeneutik. Kajian ini menunjukkan antara masalah yang kerap dibincangkan ialah sikap murid yang tidak memberi tumpuan terhadap pengajaran guru, rasa bosan, malas berusaha dan ibu bapa yang kurang mengambil berat tentang pelajaran anak mereka. Implikasi kajian kepada guru ialah menggunakan kaedah pengajaran yang bersesuaian dalam pengajaran dan pembelajaran Sains dan ibu bapa memberi tumpuan terhadap anak serta Kementerian Pendidikan perlu memberikan latihan kepada guru-guru yang mengajar Sains.
\end{abstract}

Kata kunci $\quad$ Kaedah Hermeneutik, Sikap Murid, Mata Pelajaran Sains, Pengajaran Dan Pembelajaran.

\begin{abstract}
This study analyzes the attitude of pupils and how teachers and parents can help them towards Science subject in National Tamil Primary school. The sample involves ten year five pupils in the National Tamil Primary school located in North Kinta district. This study uses the text scripts written by the respondents obtained as data and complied into a text. The texts of this study were analyzed using Hermeneutic method. This study shows arising problems often discussed, namely the attitude of students who do not focus on teachers teaching, feeling tired, lazy, and parents are less concerned about their children's education. The implications of the study for teachers is to use appropriate teaching methods in the teaching and learning Science and parents focus on the child as well as the Ministry of Education to provide training to teachers who teach Science subject.
\end{abstract}

Keywords Hermeneutic Method, Attitude Of Pupils, Science

Subject, Teaching And Learning. 


\section{PENGENALAN}

Tujuan subjek Sains diperkenalkan dalam Kurikulum Standard Sekolah Rendah (KSSR) adalah untuk membuka peluang yang luas untuk murid menimba ilmu pengetahuan dan kemahiran Sains, menerapkan kemahiran berfikir secara kreatif, kreatis dan inovatif, mengembangkan pengetahuan dan kemahiran dalam kehidupan setiap hari serta memupuk nilai-nilai murni dan semangat patriotisme. Subjek Sains tahun 5 direka bentuk untuk tujuan memperkembangkan kemahiran dan menekankan konsep Sains dan pemahaman tentang Sains kepada murid supaya celik Sains dan dapat membantu mereka untuk menguasai ilmu Sains di institusi pendidikan tinggi (Bahagian Pembangunan Kurikulum, 2014).

Pendidikan Sains membantu murid untuk memahami betapa pentingnya Sains dan kecenderungan untuk menjurus dalam sektor Sains supaya murid dapat menyemai pandangan yang positif, bertanggungjawab, bijaksana dan celik Sains dan Teknologi. Kajian yang dilakukan di peringkat antarabangsa menunjukkan pencapaian negara dalam Trends in International Mathematics and Science Study (TIMSS) berada pada tahap yang agak membimbangkan. Situasi ini merupakan suatu penggerak untuk meningkatkan tahap pencapaian murid dalam mata pelajaran Sains (Pelan Pembangunan Pendidikan Malaysia (2013 - 2025, 2013).

Hampir tiga puluh tahun yang lepas, ramai pengkaji telah melaporkan bahawa terdapat kemerosotan sikap terhadap subjek Sains dalam kalangan murid (Kamisah et al., 2007). Sikap murid terhadap kemerosostan mata pelajaran Sains telah diukur berdasarkan kebolehan murid, iaitu murid yang berkebolehan sederhana dan tinggi serta lemah. Beberapa penyelidikan tentang sikap murid terhadap Sains menyatakan bahawa motivasi yang rendah dalam kalangan murid menyebabkan murid bersikap negatif terhadap mata pelajaran ini dan menyebabkan pencapaian semakin merosot (Talib et al., 2009). Malah, terdapat juga kajian-kajian lain menyatakan bahawa faktor-faktor luaran juga penyebab kepada kemerosotan sikap murid terhadap subjek Sains. Kemerosotan sikap murid terhadap mata pelajaran Sains adalah disebabkan oleh beberapa perkara. Faktor minat murid terhadap mata pelajaran Sains, pengajaran guru di sekolah, pencapaian Sains, faktor persekitaran pembelajaran, perbezaan jantina dan interaksi murid dengan guru serta persekitaran pembelajaran bilik darjah yang turut memberi kesan ke atas sikap murid terhadap kurikulum Sains (Ali, Yager, Hacieminoglu \& Caliskan, 2013). Pembangunan dan perkembangan sikap murid terhadap mata pelajaran Sains juga berkait rapat dengan pengajaran guru melalui penggunaaan bahan-bahan mengajar (Agranovich \& Assaraf, 2013). Malah, terdapat juga murid yang seringkali memperoleh markah yang rendah apabila setiap kali ujian atau peperiksaan dijalankan.

Hakikatnya, terdapat kemerosotan murid dari segi pencapaian subjek Sains. Terdapat beberapa penyelidikan yang menyatakan bahawa terdapat beberapa faktor yang menyebabkan kemerosotan sikap murid dalam mata pelajaran Sains. 
Beberapa faktor yang dapat dilihat dan harus diberi penekanan ialah berkaitan dengan sikap murid itu sendiri. Seseorang yang ingin mengecapi kejayaan dalam bidang pendidikan bergantung kepada aspek sikap. Sikap adalah sesuatu yang boleh dipelajari untuk mempertingkatkan jati diri. Sikap adalah bahawa mata pelajaran Sains merupakan alat penyampai ilmu pengetahuan dan penting dalam pembentukan masyarakat yang mempunyai peribadi yang mulia, bermaruah tinggi dan menghayati perkara yang berbentuk dalaman dan mudah dan ia lahir di dalam sanubari kita (Hacieminoglu, Yilmaz-Tuzun \& Ertepinar, 2009).

\section{OBJEKTIF KAJIAN}

i. Mengenal pasti sikap murid tahun 5 terhadap mata pelajaran Sains di Sekolah Jenis Kebangsaan (Tamil).

ii. Mengenal pasti cara-cara guru dapat membantu murid tahun 5 dalam mata pelajaran Sains di Sekolah Jenis Kebangsaan (Tamil).

iii. Mengenal pasti cara-cara ibu bapa dapat membantu murid tahun 5 dalam mata pelajaran Sains di Sekolah Jenis Kebangsaan (Tamil).

\section{METODOLOGI KAJIAN}

Kajian ini merupakan kajian berbentuk deskriptif yang menggunakan analisis Hermeneutik. Analisis Hermeneutik merupakan kaedah kualitatif yang menekankan aspek keunikan dan kelainan dalam sesuatu kajian penyelidikan. Menurut Ragin (1994), reka bentuk kajian merujuk kepada perancangan atau pelan dalam mengumpul dan menganalisis bukti yang diperoleh bagi memastikan pengkaji dapat menjawab soalan kajian yang ingin dijawab. Reka bentuk kajian dibentuk setelah mengambil kira beberapa aspek kajian seperti objektif kajian, rangka konsep teori, soalan kajian, pemilihan bahan empirikal, prosedur metodologi, tahap kawalan dan sumber individual yang mencukupi.

Menurut Higgs et al.,(2012), fasa permulaan dalam Hermeneutik ialah proses menginterpretasikan teks secara objektif sebelum pemahaman kepada simbolsimbol tertentu yang dibuat dalam sesebuah teks. Kemudian, teks dikaitkan dengan elemen-elemen lain dalam teks dan pemahaman diletakkan untuk proses interpretasi bergantung kepada kualiti seseorang penterjemah. Menurut Suppiah (2003, 2013, 2014, 2016), Hermeneutik membolehkan pengkaji membuat interpretasi berdasarkan teori dan pengetahuan pengkaji dalam memahami teks responden yang abstrak. Dalam kaedah Hermeneutik, reka bentuk kajian boleh dibentuk seperti dalam Rajah 1. 


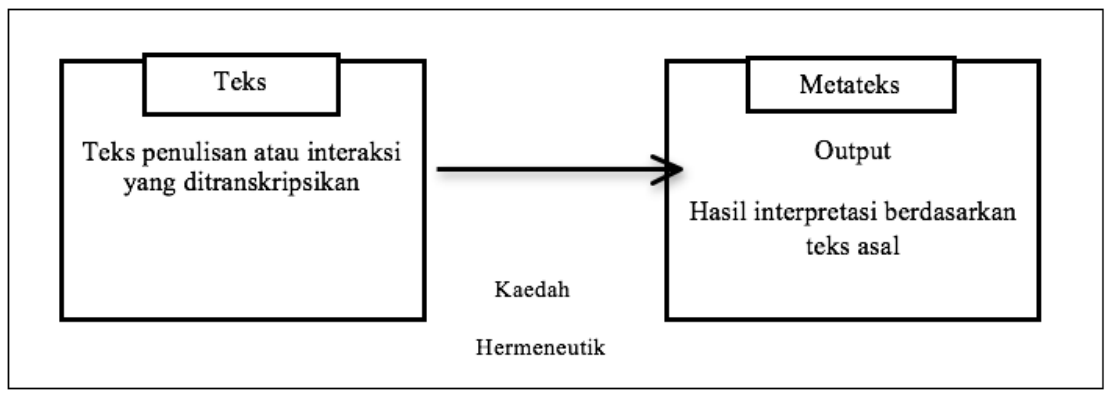

Rajah 1 Reka Bentuk Kajian Menggunakan Kaedah Hermeneutik - diadaptasi (Suppiah, 2003)

Menurut Lyons dan Coyle (2007), tugas membuat penyelidikan kualitatif adalah menarik dan suatu proses yang mencabar. Hal ini kerana melalui kajian kualitatif, data yang banyak dan berkualiti dapat diperoleh. Ia juga menyediakan peluang-peluang untuk meneroka sesuatu yang kompleks dan cara berbeza yang dapat menyedari dan menghadapi dunia sosial. Kajian berdasarkan kualitatif mengutamakan penyelidikan sebagai suatu proses dinamik dengan peranan pengkaji adalah aktif dalan proses tersebut. Pengkaji dalan konteks kajian kualitatif agak sukar untuk mengalami pengalaman sampel dan memerlukan konseptual pengkaji sendiri dalam pemahaman dalam aktiviti penginterpretasian.

Dalam kajian ini, sampel terdiri daripada 10 orang murid tahun 5 di Sekolah Jenis Kebangsaan (Tamil).

\section{DAPATAN KAJIAN}

Berikut adalah interpretasi menggunakan kaedah Hermeneutik untuk menjawab objektif kajian seperti berikut.

\section{a) Mengenal pasti sikap murid tahun 5 terhadap mata pelajaran Sains di Sekolah Jenis Kebangsaan (Tamil).}

Jadual 1 Interpretasi terhadap sikap murid tahun 5 terhadap mata pelajaran Sains di Sekolah Jeni Kebangsaan (Tamil).

\begin{tabular}{|l|l|}
\hline Teks Asal & $\begin{array}{l}\text { Interpretasi terhadap sikap murid tahun 5 } \\
\text { terhadap mata pelajaran Sains di Sekolah } \\
\text { Jenis Kebangsan (Tamil) di daerah Kinta } \\
\text { Utara. }\end{array}$ \\
\hline Soalan Kajian1: & \\
$\begin{array}{l}\text { Bagaimanakah sikap murid tahun } \\
5 \text { terhadap mata palajaran Sains di } \\
\begin{array}{l}\text { Sekolah Jenis Kebangsaan (Tamil) di } \\
\text { daerah Kinta Utara? }\end{array}\end{array}$ \\
\hline
\end{tabular}




\begin{abstract}
Responden 1
Memek muka guru yang serius dan kelihatan marah akan menakutkan murid untuk bertanya atau memberi jawapan.

Istilah-istilah dan fakta Sains yang merumitkan murid.

Pengajaran guru menyebabkan murid berasa tertekan dan keliru untuk belajar Sains dan berasa susah untuk menjawab soalan yang ditanya oleh guru. Murid berasa bosan untuk mempelajari Sains kerana disuruh mencatat nota dan menyusahkan fikiran.
\end{abstract}

Murid berasa takut akan guru yang mengajar subjek Sains. Murid juga berasa takut kerana guru akan memandang rendah terhadap murid.

Murid menghadapi masalah untuk memahami istilah-istilah Sains. Murid juga sukar untuk mengingati fakta-fakta Sains dan tidak mampu untuk menguasai dan sukar untuk mengingati pengajaran guru.

Murid menyatakan bahawa penerangan guru yang mengelirukan dan tidak memberi perhatian terhadap murid dalam mata pelajaran Sains menyebabkan murid berasa tertekan untuk belajar dan menjawab soalan yang diajukan oleh guru. Murid tidak dapat berfokus terhadap mata pelajaran Sains yang dijalankan kerana rasa bosan terhadap pengajaran guru yang seringkali mencatat nota dan membebankan fikiran.

\section{Responden 2}

Perasaan takut dan gementar apabila waktu Sains kerana guru yang seringkali bertanya soalan yang susah.

Istilah-istilah yang sukar difahami menyebabkan mata pelajaran tersebut susah.

Peranan ibu bapa dalam membantu anak amat kurang dan menyebabkan pencapaian yang tidak memuaskan.

Responden 3

Rasa cemas dan takut apabila menatap wajah guru Sains. Kesukaran untuk mengingati istilah dan fakta-fakta Sains yang terlalu banyak.

Malas dan tidak melibatkan diri secara aktif dalam aktiviti berkumpulan. Tumpuan terhadap guru semakin berkurangan semasa proses pembelajaran sedang berlangsung.
Murid ini takut untuk melihat wajah guru yang menanyakan soalan-soalan yang mencabar dan sukar dijawab.

Murid ini mendapati bahawa terdapat istilahistilah Sains yang menyukarkan untuk memahami subjek ini.

Ibu bapa murid ini tidak dapat menumpukan sepenuh perhatian terhadap pembelajaran Sains sehingga pencapaian terjejas.
Murid ini berasa cemas dan takut apabila guru Sains menjalankan pengajaran di bilik mahupun makmal Sains. Istilah Sains dan fakta yang terlalu banyak menyebabkan murid ini berasa sukar terhadap subjek tersebut.

Murid ini tidak menumpukan sepenuh perhatian terhadap guru semasa sesi pembelajaran berjalan. Murid ini tidak menumpukan perhatian terhadap guru sewaktu pembelajaran Sains. 


\section{Responden 4 \\ Takut dan rasa gementar untuk mendampingi guru kerana guru terlalu garang. Istilah-istilah dan fakta Sains amat merumitkan sehingga susah untuk dihafal. \\ Rasa semakin tertekan dan gugup dalam menjawab soalan-soalan yang mencabar. Malu untuk bertanya kerana beranggapan akan dipandang rendah oleh rakan sekelas.}

\section{Responden 5}

Ketakutan terhadap guru Sains menyebabkan murid tidak menyukai subjek ini. Peggunaan istilah yang terlalu banyak sehingga sukar untuk murid.

Kurang aktiviti yang menarik menyebabkan rasa kebosanan terhadap subjek ini. Tidak memberi tumpuan kerana tidak diberi peluang untuk menjawab soalan.

\section{Responden 6}

Pengajaran guru menyebabkan murid berasa tertekan dan keliru untuk belajar Sains. Murid berasa bosan untuk mempelajari Sains dan membebankan fikiran kerana guru sentiasa menyuruh menyalin nota.

Murid menghadapi masalah rasa malu untuk bertanya dan rendah diri terhadap subjek Sains.

Tidak melibatkan diri secara aktif dalam aktiviti berkumpulan disebabkan rasa malas. Tidak memberi tumpuan kerana tidak diberi peluang untuk menjawab soalan.
Ketakutan terhadap guru Sains yang akan memarahi murid sekirannya murid tidak dapat menjawab soalan dengan betul. Murid ini menghadapi masalah untuk mengingati istilah Sains yang terlalu banyak dan luas.

Murid ini berasa terlalu tertekan dan stress kerana terlalu banyak perkara yang perlu diketahui dan sukar menjawab soalan.

Murid ini berasa takut akan guru Sains yang terlalu garang terhadap muridsewaktu pengajaran dilaksanakan.Istilah-istilah yang digunakan terlalu banyak menyukarkan murid terhadappembelajaran Sains.

Murid ini menghadapi rasa kebosanan terhadap aktiviti yang tidak menarik perhatiannya. Semasa pembelajaran dijalankan, murid ini tidak memberi tunpuan kerana tidak diberi peluang oleh guru tersebut.

Murid menyatakan bahawa penerangan guru yang mengelirukan dan guru tidak memberi perhatian terhadap murid ini dalam mata pelajaran Sains menyebabkan murid berasa tertekan. Murid tidak dapat berfokus terhadap mata pelajaran Sains yang dijalankan kerana rasa bosan terhadap pengajaran guru yang seringkali mencatat nota.

Murid ini berasa malu dan rendah diri semasa pembelajaran Sains kerana murid tidak faham pengajaran guru dan rasa rendah diri kerana kurang yakin terhadap diri sendiri.

Topik dan aktiviti yang tidak melibatkan murid secara aktif menyebabkan murid rasa malas. Murid ini tidak diberi peluang untuk menjawab soalan menyebabkan murid ini tidak memberi tumpuan sepenuhnya. 


\section{Responden 7 \\ Rasa takut akan guru Sains menyebabkan murid tidak menyukai subjek ini. Penggunaan istilah dan fakta yang banyak menyukarkan murid untuk mengingatinya. \\ Aktiviti yang dijalankan tidak menarik menyebabkan rasa kebosanan terhadap subjek ini. Tidak memberi tumpuan kerana tidak diberi peluang untuk menjawab soalan. \\ Perasaan bimbang dan berdebar-debar terhadap Sains sentiasa timbul dalam diri menyebabkan rasa tidak suka terhadap subjek ini.}

\section{Responden 8}

Muka guru yang serius menakutkan murid untuk bertanya atau memberi jawapan. Istilah-istilah dan fakta-fakta Sains yang merumitkan murid.

Rasa tertekan dengan soalan-soalan yang mencabar dan mengelirukan. Rasa malas untuk belajar timbul dalam diri kerana tidak memahami pelajaran Sains yang diajar.

\section{Responden 9}

Takut dan rasa gementar untuk mendampingi guru kerana guru terlalu garang. Tanggapan bahawa Sains susah kerana terlalu banyak istilah yang perlu dihafal.

Rasa tertekan kerana harapan ibu bapa terhadapnya terlalu tinggi. Tidak memberikan tumpuan sepenuhnya terhadap pengajaran guru dan tidak dapat menyiapkan tugasan yang diberikan.

Kebimbangan terhadap Sains menyumbang kepada sikap benci terhadap subjek ini.
Guru terlalu garang sehingga murid berasa terlalu takut dan tiada keyakinan diri. Istilahistilah yang digunakan terlalu banyak sehingga susah bagi murid untuk belajar Sains.

Murid ini menghadapi rasa kebosanan dan lebih cenderung untuk tidak melibatkan diri dalam sebarang aktiviti semasa pembelajaran dijalankan, murid ini tidak memberi tumpuan kerana tidak diberi peluang oleh guru tersebut.

Rasa kebimbangan dan keresahan menyebabkan murid tidak menyukai mata pelajaran Sains.

Murid berasa takut akan guru Sains kerana guru akan memandang rendah terhadap murid. Murid menghadapi masalah untuk memahami istilahistilah dan fakta Sains.

Murid menyatakan bahawa soalan yang ditanya sukar dan menyebabkan murid berasa tertekan dalam pemahaman pembelajaran Sains.

Murid ini menghadapi masalah guru yang terlalu garang menjadikan murid sentiasa gelisah dan takut. Banyak istilah yang perlu dihafal menyebabkan murid ini tidak bersemangat untuk belajar.

Murid ini rasa bersalah kerana gagal mencapai apa yang dijangkakan serta rasa gelisah menunggu keputusan ujian. Murid ini kelihatan tidak dapat menumpukan sepenuh perhatian terhadap pembelajaran Sains.

Keresahan dan kebimbangan terhadap Sains menyebabkan murid ini berasa susah hati. 


\begin{tabular}{|c|c|}
\hline Responden 10 & \\
\hline $\begin{array}{l}\text { Ketiadaan kebebasan dalam kelas } \\
\text { menyebabkan murid takut terhadap } \\
\text { guru Sains dan takut untuk belajar. } \\
\text { Tidak dapat memahami istilah } \\
\text { dalam Sains menyebabkan tidak ada } \\
\text { semangat untuk belajar. }\end{array}$ & $\begin{array}{l}\text { Guru yang serius dan berwajah garang } \\
\text { menyebabkan murid ini berasa takut sebaik } \\
\text { sahaja sesi pembelajaran bermula. Murid ini } \\
\text { menghadapi masalah untuk belajar Sains kerana } \\
\text { sukar untuk memahami istilah. }\end{array}$ \\
\hline $\begin{array}{l}\text { Rasa bosan dan mengantuk semasa } \\
\text { pembelajaran di bilik darjah kerana } \\
\text { tidak memahami pengajaran guru. }\end{array}$ & $\begin{array}{l}\text { Pengajaran guru sukar difahami menyebabkan } \\
\text { murid ini berasa bosan dan mengantuk lalu tidak } \\
\text { fokus dalam pelajaran. }\end{array}$ \\
\hline $\begin{array}{l}\text { Malas untuk melakukan aktiviti yang } \\
\text { diberikan oleh guru. }\end{array}$ & $\begin{array}{l}\text { Murid ini enggan melakukan aktiviti yang } \\
\text { diberikan guru kerana rasa malas dan tidak } \\
\text { hendak berfikir dengan sendiri. }\end{array}$ \\
\hline $\begin{array}{l}\text { Rasa kecewa semasa bersama-sama } \\
\text { dengan kawan-kawan kerana akan } \\
\text { diperli oleh mereka kerana pencapaian } \\
\text { yang kurang memuaskan. }\end{array}$ & $\begin{array}{l}\text { Pencapaian yang kurang memuaskan } \\
\text { menyebabkan murid ini diejek oleh rakan dan } \\
\text { membawa kepada rasa kecewa. }\end{array}$ \\
\hline $\begin{array}{l}\text { Perasaan berdebar-debar dan bimbang } \\
\text { terhadap Sains sentiasa timbul dalam } \\
\text { diri menyebabkan rasa tidak suka } \\
\text { terhadap subjek ini. } \\
\text { Ibu bapa kurang memberi perhatian } \\
\text { yang sepenuhnya terhadap } \\
\text { pembelajaran anak mereka. }\end{array}$ & $\begin{array}{l}\text { Kerisauan murid terhadap Sains dapat ditonjolkan } \\
\text { melalui rasa kebimbangan menyebabkan murid } \\
\text { ini tidak menyukai pembelajaran Sains. } \\
\text { Penglibatan ibu bapa terhadap mata pelajaran } \\
\text { Sains murid ini kurang menyebabkan murid ini } \\
\text { berasa susah hati. }\end{array}$ \\
\hline
\end{tabular}

Hasil data menunjukkan bahawa seramai sembilan orang responden menyatakan guru yang garang dan serius menakutkan murid untuk belajar subjek Sains. Seramai sembilan orang responden pula menyatakan bahawa mereka mengalami kesukaran untuk mengingati istilah dan fakta. Pengkaji mendapati bahawa masalah yang ketara dihadapi oleh murid dalam pengajaran dan pembelajaran Sains di sekolah ialah masalah sukar memberikan tumpuan kerana sebanyak lapan orang responden menyatakan masalah yang sama. Pengkaji mendapati bahawa rasa kebosanan terhadap pengajaran guru terhadap mata pelajaran Sains merupakan masalah yang dihadapi oleh responden. Akhir sekali, responden menyatakan bahawa rasa tertekan dan keliru terhadap pengajaran guru, kebimbangan dan keresahan terhadap Sains, rasa malu dan rendah diri apabila guru memandang rendah terhadap murid juga merupakan sikap utama yang dihadapi oleh murid-murid tahun lima.

Pengkaji mendapati bahawa masalah yang ketara dihadapi oleh murid dalam pengajaran dan pembelajaran Matematik di sekolah ialah masalah rasa malas untuk melakukan aktiviti dan eksperimen kerana sebanyak enam orang responden menyatakan masalah yang sama. Selain itu, seramai lima orang responden menyatakan bahawa mereka menghadapi masalah sikap kecewa dan gementar terhadap Sains. Masalah murid kurangnya perhatian daripada ibu bapa terhadap mata pelajaran Sains dinyatakan oleh enam orang responden. 


\section{b) Mengenal pasti cara-cara guru dapat membantu murid tahun 5 dalam mata pelajaran Sains di Sekolah Jenis Kebangsaan (Tamil).}

Jadual 2 Interpretasi terhadap cara-cara guru dapat membantu murid tahun 5 dalam mata pelajaran Sains di Sekolah Jenis Kebangsaan (Tamil)

\begin{tabular}{|c|c|}
\hline Teks Asal & $\begin{array}{l}\text { Interpretasi terhadap cara-cara guru dapat } \\
\text { membantu murid tahun } 5 \text { dalam mata } \\
\text { pelajaran Sains di Sekolah Jenis Kebangsaan } \\
\text { (Tamil) }\end{array}$ \\
\hline \\
\hline \multicolumn{2}{|l|}{$\begin{array}{l}\text { Bagaimanakah guru dapat membantu } \\
\text { murid tahun } 5 \text { dalam mata pelajaran } \\
\text { Sains di SJK(T)? }\end{array}$} \\
\hline \multicolumn{2}{|l|}{ Responden 1} \\
\hline $\begin{array}{l}\text { Kaedah Pembelajaran } \\
\text { dapat meningkatkan peratif } \\
\text { yang mendalam tentang kemahiran- } \\
\text { kemahiran yang terdapat dalam Sains. }\end{array}$ & $\begin{array}{l}\text { Melalui kaedah ini pemahaman murid akan } \\
\text { meningkat terhadap kemahiran Sains lebih } \\
\text { mendalam apabila guru mengaplikasikan } \\
\text { pembelajaran koperatif. Murid dapat } \\
\text { meningkatkan pemahaman mereka tentang } \\
\text { konsep Sains dan dapat menerangkan konsep ini } \\
\text { dengan rakan dalam kumpulan. }\end{array}$ \\
\hline $\begin{array}{l}\text { Penggunaan Teknologi Maklumat dan } \\
\text { Komunikasi dalam pengajaran Sains } \\
\text { dapat merangsang minda murid untuk } \\
\text { belajar dan seterusnya memupuk } \\
\text { semangat motivasi. }\end{array}$ & $\begin{array}{l}\text { Pengajaran dan pembelajaran Sains akan lebih } \\
\text { menarik apabila guru menggunakan teknologi } \\
\text { maklumat untuk merangsang minda murid dan } \\
\text { murid berasa terhibur dengan paparan slaid- } \\
\text { slaid yang berwarna-warni. }\end{array}$ \\
\hline $\begin{array}{l}\text { Penerapan kaedah Kemahiran Berfikir } \\
\text { Secara Kreatif dan Kritis dalam } \\
\text { menyelesaikan masalah dan meluaskan } \\
\text { tahap pemikiran murid. }\end{array}$ & $\begin{array}{l}\text { Kaedah KBAT merupakan proses mental yang } \\
\text { dapat meningkatkan kemahiran berfikir secara } \\
\text { kreatif dan kritis dalam kalangan murid. Murid } \\
\text { dapat mencari idea-idea untuk menyelesaikan } \\
\text { masalah yang dihadapi dalam kehidupan } \\
\text { seharian. }\end{array}$ \\
\hline $\begin{array}{l}\text { Konsep Pembelajaran Akses Kendiri } \\
\text { (PAK) dapat membolehkan murid } \\
\text { belajar secara kendiri melalui } \\
\text { penggunaan bahan pembelajaran. }\end{array}$ & $\begin{array}{l}\text { Murid ini diberi peluang memilih aktiviti, } \\
\text { menilai hasil kerja dan memantau kemajuan } \\
\text { mereka sendiri agar mereka bertanggungjawab } \\
\text { dan berdikari atas pembelajaran melalui } \\
\text { pembelajaran akses kendiri. }\end{array}$ \\
\hline $\begin{array}{l}\text { Memperbanyakkan aktiviti } \\
\text { pembelajaran yang berasaskan projek } \\
\text { atau project-based learning }(P B L) \text {. }\end{array}$ & $\begin{array}{l}\text { Pembelajaran Berasaskan Projek dapat } \\
\text { menggalakkan murid untuk berfikir dan } \\
\text { melibatkan dalam proses pengajaran yang aktif } \\
\text { dan menyeronokkan. }\end{array}$ \\
\hline $\begin{array}{l}\text { Guru lebih yakin cara penyampaian } \\
\text { pengajaran Sains melalui kaedah ini } \\
\text { lebih berkesan daripada kaedah biasa. }\end{array}$ & $\begin{array}{l}\text { Penyampaian pengajaran } \\
\text { pendekatan konstruktivisme } \\
\text { daripada kaedah biasa. }\end{array}$ \\
\hline
\end{tabular}




\begin{tabular}{|c|c|}
\hline Responden 2 & \\
\hline $\begin{array}{l}\text { Kaedah ini mendorong murid } \\
\text { membimbing rakan-rakan sekumpulan } \\
\text { supaya semua murid dapat menguasai } \\
\text { Sains. }\end{array}$ & $\begin{array}{l}\text { Matlamat yang telah ditetapkan dapat dicapai } \\
\text { apabila rakan-rakan membimbing murid dan } \\
\text { pemahaman murid terhadap kemahiran Sains } \\
\text { akan lebih mendalam. }\end{array}$ \\
\hline $\begin{array}{l}\text { Penggunaan ICT dalam pengajaran dan } \\
\text { pembelajaran Sains membantu murid } \\
\text { dan merangsang minda untuk belajar } \\
\text { Sains. }\end{array}$ & $\begin{array}{l}\text { Guru ini menggunakan kemudahan ICT untuk } \\
\text { menarik minat murid dan merangsang perasaan } \\
\text { ingin tahu murid-murid. }\end{array}$ \\
\hline $\begin{array}{l}\text { Kaedah penyampaian yang sesuai } \\
\text { meningkatkan pencapaian objektif } \\
\text { Sains. }\end{array}$ & $\begin{array}{l}\text { KBAT dapat membantu murid berfikir dengan } \\
\text { lebih kritis dalam menyelesaikan masalah. }\end{array}$ \\
\hline $\begin{array}{l}\text { Kaedah bermain memberikan } \\
\text { keseronokan kepada murid untuk } \\
\text { terus belajar dalam suasana yang lebih } \\
\text { selesa. }\end{array}$ & $\begin{array}{l}\text { Rasa terhibur dan seronok menerusi kaedah } \\
\text { ini dan keinginan untuk belajar Sains lebih } \\
\text { cenderung. }\end{array}$ \\
\hline $\begin{array}{l}\text { Meningkatkan motivasi untuk belajar } \\
\text { dan murid lebih aktif serta dapat } \\
\text { meningkatkan tentang kemahiran- } \\
\text { kemahiran Sains dalam kaedah PBL. }\end{array}$ & $\begin{array}{l}\text { Peningkatan motivasi untuk terus belajar } \\
\text { semakin ketara dan penglibatan secara aktif } \\
\text { dalam aktiviti berkumpulan. }\end{array}$ \\
\hline $\begin{array}{l}\text { Guru dilatih untuk bekerja dalam bidang } \\
\text { Sains dan Teknologi, Kejuruteraan dan } \\
\text { Matematik (STEM) dan berperanan } \\
\text { untuk memupuk minat murid. }\end{array}$ & $\begin{array}{l}\text { Guru berperanan untuk menanam minat kepada } \\
\text { murid untuk menyambung pelajaran dalam } \\
\text { bidang berkaitan dengan STEM sejak dari } \\
\text { sekolah lagi. }\end{array}$ \\
\hline $\begin{array}{l}\text { Pengajaran menyentuh tentang isi } \\
\text { kandungan dapat disampaikan dengan } \\
\text { efektif. }\end{array}$ & $\begin{array}{l}\text { Teknik dan strategi pengajaran konstruktivisme } \\
\text { melibatkan penyampaian isi kandungan dapat } \\
\text { disampaikan dengan berkesan. }\end{array}$ \\
\hline
\end{tabular}




\begin{tabular}{|c|c|}
\hline Responden 3 & \\
\hline $\begin{array}{l}\text { Pembelajaran koperatif dalam Sains } \\
\text { dapat meningkat penyertaan murid- } \\
\text { murid dalam pembelajaran. }\end{array}$ & $\begin{array}{l}\text { Kaedah ini menggalakkan penglibatan murid } \\
\text { secara aktif dalam pembelajaran dan berkongsi } \\
\text { maklumat bersama rakan-rakan. }\end{array}$ \\
\hline $\begin{array}{l}\text { Pengajaran dan pembelajaran lebih } \\
\text { mudah dengan ICT dan murid dapat } \\
\text { menguasai Sains dengan lebih cepat. }\end{array}$ & $\begin{array}{l}\text { Penggunaan ICT dalam pengajaran memudahkan } \\
\text { guru untuk menjalankan aktiviti yang dirancang } \\
\text { berjalan dengan lancar. }\end{array}$ \\
\hline $\begin{array}{l}\text { Murid melibatkan diri dalam aktiviti } \\
\text { pembelajaran secara aktif ke arah } \\
\text { penguasaan KBAT. }\end{array}$ & $\begin{array}{ll}\text { Penglibatan murid secara aktif dalam } \\
\text { pembelajaran kea rah penguasaan idea-idea } \\
\text { KBAT. }\end{array}$ \\
\hline $\begin{array}{l}\text { Proses pengajaran dan pembelajaran } \\
\text { lebih mudah dan memberikan } \\
\text { penekanan yang lebih mendalam } \\
\text { kepada murid tentang kandungan } \\
\text { Sains. }\end{array}$ & $\begin{array}{l}\text { Penekanan kepada perkembangan murid } \\
\text { dan memudahkan proses pengajaran dan } \\
\text { pembelajaran yang mendalam tentang isi } \\
\text { kandungan Sains. }\end{array}$ \\
\hline $\begin{array}{l}\text { Keyakinan murid lebih terserlah } \\
\text { dengan kaedah lakonan dan murid } \\
\text { terhibur. }\end{array}$ & $\begin{array}{l}\text { Guru membantu murid membina keyakinan } \\
\text { diri dengan mengaplikasikan teknik ini dalam } \\
\text { pembelajaran Sains. }\end{array}$ \\
\hline $\begin{array}{l}\text { Teknik penyoalan menggalakkan } \\
\text { pemikiran murid menerusi pendekatan } \\
\text { konstruktivisme. }\end{array}$ & $\begin{array}{l}\text { Pemdekatan ini menekankan kepada kaedah } \\
\text { penyoalan guru dapat meningkatkan tahap } \\
\text { pemikiran murid melalui pendekatan } \\
\text { konstruktivisme. }\end{array}$ \\
\hline $\begin{array}{l}\text { Pembelajaran yang melibatkan proses } \\
\text { meneroka kehidupan secara semula } \\
\text { jadi dan akan menggalakkan penyoalan } \\
\text { dan melakukan eksperimen untuk } \\
\text { mendapatkan pengetahuan baharu. }\end{array}$ & $\begin{array}{l}\text { Penyoalan menggalakkan pembelajaran yang } \\
\text { melibatkan penerokaan kehidupan secara } \\
\text { semula jadi dan menjalankan eksperimen secara } \\
\text { berkumpulan untuk memperoleh pengetahuan } \\
\text { baharu dalam dunia Sains. }\end{array}$ \\
\hline
\end{tabular}




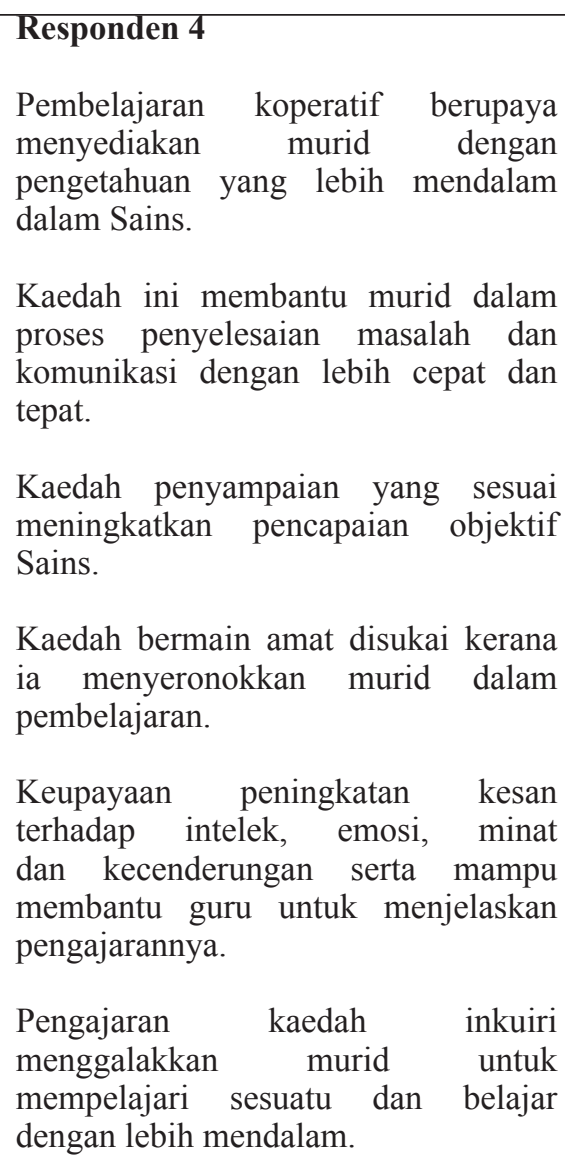

Pembelajaran menyediakan

koperatif berupaya pengetahuan yang lebih mendalam dalam Sains.

Kaedah ini membantu murid dalam proses penyelesaian masalah dan komunikasi dengan lebih cepat dan tepat.

Kaedah penyampaian yang sesuai meningkatkan pencapaian objektif Sains.

Kaedah bermain amat disukai kerana ia menyeronokkan murid dalam pembelajaran.

Keupayaan peningkatan kesan terhadap intelek, emosi, minat dan kecenderungan serta mampu membantu guru untuk menjelaskan pengajarannya.

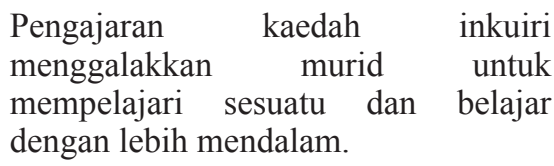

\section{Responden 5}

Pembelajaran Sains melalui kaedah koperatif membolehkan murid mahir dalam menjawab dan menyiapkan latihan.

Proses pengajaran Sains lebih mudah dengan pengaplikasian ICT.

Murid melibatkan diri dalam aktiviti pembelajaran secara aktif ke arah KBAT dan mampu menyelesaikan masalah.

Kaedah ini memupuk sikap ingin tahu, membina keyakinan diri dan mempunyai kemahiran Sains yang kukuh.
Keupayaan untuk menguasai pengetahuan tentang Sains secara luas dalam kalangan murid.

ICT dapat memudahkan proses menyelesaikan masalah dalam pengajaran dan pembelajaran dengan lebih mudah dan tepat.

Peningkatan dalam pencapaian matlamat Sains secara efektif.

Pembelajaran Sains lebih diminati oleh murid sekiranya guru mempraktikkan teknik bermain.

Pengajaran dapat dilaksanakan dengan berkesan menerusi peningkatan kesan terhadap intelek, emosi dan minat.

Kaedah ini membolehkan murid untuk mempelajari sesuatu dan memperoleh lebih banyak ilmu pengetahuan.

Pembelajaran koperatif menggalakkan murid untuk mahir dalam menjawab soalan yang dikemukakan oleh guru.

Penggunaan ICT dalam pengajaran dan pembelajaran memupuk minat dan menarik perhatian murid.

Penglibatan murid secara aktif dalam pembelajaran KBAT dan merangsang murid untuk berfikir dalam menyelesaikan masalah yang rumit.

Sikap ingin tahu dan keyakinan diri dapat dibina dalam diri murid melalui kaedah konstruktivisme. 


\begin{tabular}{|l|l|}
\hline Responden 6 & \\
$\begin{array}{l}\text { Pemahaman murid terhadap Sains } \\
\text { lebih mendalam dan penglibatan secara } \\
\text { aktif dengan kaedah koperatif. }\end{array}$ & $\begin{array}{l}\text { Kaedah koperatif dapat meningkatkan } \\
\text { kefahaman murid terhadap kemahiran Sains dan } \\
\text { memupuk penglibatan murid secara aktif dalam } \\
\text { kerja berpasukan. }\end{array}$ \\
$\begin{array}{l}\text { Penggunaan ICT dapat mewujudkan } \\
\text { suasana pembelajaran Sains yang } \\
\text { seronok, mencabar dan berbentuk } \\
\text { penerokaan. }\end{array}$ & $\begin{array}{l}\text { Pembelajaran Sains menjadi lebih seronok } \\
\text { dan membolehkan murid lebih berminat untuk } \\
\text { mempelajari Sains serta dapat merangsang } \\
\text { minda untuk belajar. }\end{array}$ \\
$\begin{array}{l}\text { Kaedah KBAT digunakan sebagai } \\
\text { alat berfikir dalam pengajaran dan } \\
\text { pembelajaran kemahiran Sains yang } \\
\text { berkesan dan sesuai dengan aras } \\
\text { kognitif murid. }\end{array}$ & $\begin{array}{l}\text { Kemahiran Sains dapat dikuasai dan } \\
\text { diselaraskan dengan aras kognitif murid secara } \\
\text { efektif dan membolehkan murid berfikir dan } \\
\text { mampu mengambil keputusan yang lebih baik. }\end{array}$ \\
$\begin{array}{l}\text { Pembelajaran akses kendiri memupuk } \\
\text { sikap positif terhadap pembelajaran } \\
\text { Sains. }\end{array}$ & $\begin{array}{l}\text { Murid yang mempunyai konsep kendiri } \\
\text { positif mempunyai sikap yang baik dan sering } \\
\text { memperoleh kejayaan. }\end{array}$ \\
$\begin{array}{l}\text { Sikap dan tingkah laku murid } \\
\text { dapat dibentuk melalui kaedah } \\
\text { konstruktivisme. }\end{array}$ & $\begin{array}{l}\text { Penekanan kepada tingkah laku murid dan } \\
\text { aktiviti mental dalam pembelajaran Sains } \\
\text { melalui konstruktivisme. }\end{array}$ \\
$\begin{array}{l}\text { Kaedah ini dapat menghubungkaitkan } \\
\text { apa yang dipelajari dalam Sains dengan } \\
\text { kehidupan harian murid. }\end{array}$ & $\begin{array}{l}\text { Kebolehan untuk menghubungkait pelajaran } \\
\text { Sains yang dipelajari dengan kehidupan } \\
\text { seharian. }\end{array}$ \\
\hline
\end{tabular}




\begin{tabular}{|c|c|}
\hline Responden 7 & \\
\hline $\begin{array}{l}\text { Pembelajaran koperatif dalam Sains } \\
\text { dapat meningkat penyertaan murid- } \\
\text { murid dalam pembelajaran ICT } \\
\text { dalam Sains dapat meningkatkan } \\
\text { daya kreativiti, inovasi dan imaginasi } \\
\text { murid secara universal. }\end{array}$ & $\begin{array}{l}\text { Kaedah pembelajaran koperatif } \\
\text { menggalakkan penglibatan murid secara aktif } \\
\text { dalam pembelajaran dan berkongsi maklumat } \\
\text { bersama rakan-rakan. Pemahaman ICT dapat } \\
\text { meningkatkan kreativiti dan imaginasi murid } \\
\text { dalam kemahiran Sains. }\end{array}$ \\
\hline $\begin{array}{l}\text { KBAT mengarah murid ke arah } \\
\text { membentuk pemahaman Sains secara } \\
\text { tersendiri. }\end{array}$ & $\begin{array}{l}\text { Murid diarah untuk membentuk pemahaman } \\
\text { dan kemahiran Sains melalui kaedah ini. }\end{array}$ \\
\hline $\begin{array}{l}\text { Kaedah bermain dapat meningkatkan } \\
\text { kemahiran bersosial terhadap Sains. }\end{array}$ & $\begin{array}{l}\text { Penerapan kaedah bermain ini dapat } \\
\text { memupuk interaksi antara rakan dan dapat } \\
\text { mengawal emosi. }\end{array}$ \\
\hline $\begin{array}{l}\text { Mewujudkan lebih banyak peluang } \\
\text { untuk belajar di peringkat tinggi. }\end{array}$ & $\begin{array}{l}\text { Peluang belajar di peringkat lebih tinggi } \\
\text { wujud menerusi pembelajaran Sians. }\end{array}$ \\
\hline $\begin{array}{l}\text { Teknik penyoalan menggalakkan } \\
\text { pemikiran murid menerusi } \\
\text { pendekatan konstruktivisme. }\end{array}$ & $\begin{array}{l}\text { Kaedah penyoalan dapat melahirkan murid } \\
\text { yang berfikir kea rah penyelesaian masalah } \\
\text { dan bergiat aktif dalam kerja berkumpulan. }\end{array}$ \\
\hline $\begin{array}{l}\text { Motivasikan murid dan merangsang } \\
\text { minat murid untuk belajar melalui } \\
\text { kaedah inkuiri. }\end{array}$ & $\begin{array}{l}\text { Kaeah ini dapat memotivasikan murid dan } \\
\text { merangsang minat murid untuk terus pelajar. }\end{array}$ \\
\hline
\end{tabular}




\begin{tabular}{|c|c|}
\hline Responden 8 & \\
\hline $\begin{array}{l}\text { Kaedah pembelajaran ini } \\
\text { meningkatkan pemahaman yang } \\
\text { mendalam tentang kemahiran dan } \\
\text { konsep Sains. }\end{array}$ & $\begin{array}{l}\text { Pemahaman murid dapat meningkat terhadap } \\
\text { kemahiran dan konsep Sains melalui } \\
\text { pembelajaran koperatif. }\end{array}$ \\
\hline $\begin{array}{l}\text { Penggunaan ICT akan menggalakkan } \\
\text { pembelajaran terarah kendiri dalam } \\
\text { murid terhadap Sains. }\end{array}$ & $\begin{array}{l}\text { Pembelajaran Sains akan lebih menarik dan } \\
\text { menggalakkan pembelajaran terarah kendiri } \\
\text { melalui penggunaan ICT. }\end{array}$ \\
\hline $\begin{array}{l}\text { Penerokaan tentang cara } \\
\text { penyelesaian yang lebih mendalam } \\
\text { untuk menyelesaikan masalah } \\
\text { tersebut secara sendiri. }\end{array}$ & $\begin{array}{l}\text { Murid dapat meneroka cara penyelesaian } \\
\text { yang lebih mendalam untuk menyelesaikan } \\
\text { masalah tersebut melalui KBAT. }\end{array}$ \\
\hline $\begin{array}{l}\text { Komunikasi dalam kalangan } \\
\text { murid dapat diperbaiki melalui } \\
\text { pembelajaran berasaskan projek. }\end{array}$ & $\begin{array}{l}\text { Komunikasi dapat membolehkan interaksi } \\
\text { sesama rakan dapat dipertingkatkan melalui } \\
\text { pembelajaran Sains. }\end{array}$ \\
\hline $\begin{array}{l}\text { Pembelajaran berasaskan dunia } \\
\text { yang sebenar membolehkan murid } \\
\text { memilih kerjaya sejak di bangku } \\
\text { sekolah lagi. } \\
\text { Kaedah konstruktivisme } \\
\text { membolehkan murid menyesuaikan } \\
\text { pengetahuan yang dipelajari dengan } \\
\text { pengetahuan sedia ada. }\end{array}$ & $\begin{array}{l}\text { Kaedah konstruktivisme dapat digunakan } \\
\text { untuk menyesuaikan dengan pengetahuan } \\
\text { yang sedia ada dengan pengatahuan yang } \\
\text { dipelajari. }\end{array}$ \\
\hline
\end{tabular}




\begin{tabular}{|c|c|}
\hline Responden 9 & \\
\hline $\begin{array}{l}\text { Pembelajran koperatif memberi } \\
\text { peluang untuk murid berinteraksi } \\
\text { antara satu sama lain dan boleh belajar } \\
\text { melalui pengalaman sendiri. }\end{array}$ & $\begin{array}{l}\text { Peluang untuk berkomunikasi antara murid dan } \\
\text { kebolehan untuk belajar melalui pengalaman } \\
\text { diperoleh melalui pembelajaran koperatif. }\end{array}$ \\
\hline $\begin{array}{l}\text { Pengajaran dan pembelajaran lebih } \\
\text { menyeronokkan dengan ICT dan murid } \\
\text { dapat menguasai Sains dengan lebih } \\
\text { mudah. }\end{array}$ & $\begin{array}{l}\text { Penggunaan ICT dapat menarik perhatian murid } \\
\text { untuk belajar dan mudah untuk mempelajari } \\
\text { sesuatu kemahiran Sains. }\end{array}$ \\
\hline $\begin{array}{l}\text { Peluang untuk memikirkan cara } \\
\text { penyelesaian, berkongsi kaedah- } \\
\text { kaedah penyelesaian masalah terhadap } \\
\text { satu situasi. }\end{array}$ & $\begin{array}{l}\text { Cara-cara penyelesaian masalah dapat difikirkan } \\
\text { dalam jangka masa yang singkat. }\end{array}$ \\
\hline $\begin{array}{l}\text { Melalui kaedah PBL, murid } \\
\text { menjalankan aktiviti pembelajaran } \\
\text { dengan penuh minat dan menumpukan } \\
\text { perhatian dalam situasi yang sebenar. }\end{array}$ & $\begin{array}{l}\text { Pembelajaran ini dapat memupuk minat murid } \\
\text { dan tumpuan yang sepenuhnya dalam pelajaran } \\
\text { Sains. }\end{array}$ \\
\hline $\begin{array}{l}\text { Kaedah lakonan membantu dalam } \\
\text { pembentukan sikap dan sahsiah murid } \\
\text { dalam pembelajaran Sains. }\end{array}$ & $\begin{array}{l}\text { Pembentukan sikap dan sahsiah murid dapat } \\
\text { dibentuk dalam pembelajaran subjek Sains. }\end{array}$ \\
\hline Responden 10 & \\
\hline $\begin{array}{l}\text { Keyakinan diri dapat dipertingkatkan } \\
\text { melalui kaedah pembelajaran koperatif. }\end{array}$ & $\begin{array}{l}\text { Pembelajaran koperatif dapat membina } \\
\text { keyakinan diri murid dalam memperoleh } \\
\text { pencapaian yang tinggi. }\end{array}$ \\
\hline $\begin{array}{l}\text { Penggunaan ICT dapat merangsang } \\
\text { murid untuk belajar secara berkesan } \\
\text { dengan bimbingan yang minimum. }\end{array}$ & $\begin{array}{l}\text { Pembelajaran Sains akan menarik dan } \\
\text { merangsang murid untuk belajar dengan lebih } \\
\text { efektif dengan bimbingan yang minimum oleh } \\
\text { guru. }\end{array}$ \\
\hline $\begin{array}{l}\text { KBAT dapat meningkatkan keyakinan } \\
\text { diri dalam penyelesaian masalah Sains. }\end{array}$ & $\begin{array}{l}\text { KBAT dapat membina keyakinan diri dalam } \\
\text { menyelesaikan masalah-masalah yang berkaitan } \\
\text { dengan Sains. }\end{array}$ \\
\hline $\begin{array}{l}\text { Murid berpeluang untuk memilih } \\
\text { aktiviti melalui Konsep Pembelajaran } \\
\text { Akses Kendiri dan membolehkan } \\
\text { murid belajar secara kendiri melalui } \\
\text { penggunaan bahan pembelajaran. }\end{array}$ & $\begin{array}{l}\text { Peluang untuk memilih aktiviti, menilai hasil } \\
\text { kerja dan memantau kemajuan murid lebih } \\
\text { terserlah melalui Konsep Pembelajaran Akses } \\
\text { Kendiri. }\end{array}$ \\
\hline $\begin{array}{l}\text { Pembelajaran berasaskan dunia yang } \\
\text { sebenar membolehkan murid memilih } \\
\text { kerjaya sejak kecil lagi. }\end{array}$ & $\begin{array}{l}\text { Kerjaya boleh ditentukan berdasarkan minat } \\
\text { murid sejak di bangku sekolah rendah lagi. }\end{array}$ \\
\hline
\end{tabular}

Hasil pengumpulan data serta interpretasi yang telah dilakukan, pengkaji mendapati terdapat sepuluh cara guru dapat membantu murid dalam mata pelajaran 
Sains di Sekolah Jenis Kebangsaan (Tamil). Penyelidik mendapati bahawa sepuluh responden menyatakan bahawa cara terbaik membantu murid dalam pengajaran dan pembelajaran adalah menggunakan kaedah koperatif, penggunaan teknologi maklumat dan komunikasi, penerapan kemahiran berfikir aras tinggi (KBAT) dalam pengajaran dan pembelajaran dan pendekatan konstruktivisme yang mampu membantu murid. Selain itu, terdapat enam responden menyatakan memperbanyakkan aktiviti pembelajaran yang berasaskan projek dan enam responden lagi tentang kaedah inkuiri penemuan dalam pengajaran dan pembelajaran Sains.

Seterusnya pengkaji juga mendapati lima responden menyatakan bahawa kaedah bermain dalam pembelajaran, konsep pembelajaran askses kendiri, guru Sains dilatih dalam bidang STEM dan kaedah lakonan dalam pengajaran dan pembelajaran juga merupakan cara-cara yang digunakan untuk membantu murid dalam Sains di Sekolah Jenis Kebangsaan (Tamil) bagi mata pelajaran Sains seperti Jadual 2.

\section{c) Mengenal pasti cara-cara ibu bapa dapat membantu murid tahun 5 dalam mata pelajaran Sains di Sekolah Jenis Kebangsaan (Tamil).}

Jadual 3 Interpretasi terhadap cara-cara ibu bapa dapat membantu murid tahun 5 dalam mata pelajaran Sains di Sekolah Jenis Kebangsaan (Tamil).

\begin{tabular}{|l|l|}
\hline Teks Asal & $\begin{array}{l}\text { Interpretasi terhadap cara-cara ibu bapa } \\
\text { dapat membantu murid tahun 5 dalam } \\
\text { mata pelajaran Sains di Sekolah Jenis } \\
\text { Kebangsaan (Tamil). }\end{array}$ \\
\hline $\begin{array}{l}\text { Soagaimanakah ibu bapa dapat membantu } \\
\text { murid tahun 5 dalam mata pelajaran } \\
\text { Sains? }\end{array}$ & \\
Responden 1 & \\
$\begin{array}{l}\text { Penglibatan ibu bapa dalam membentuk } \\
\text { sikap positif terhadap subjek Sains. }\end{array}$ & $\begin{array}{l}\text { Keterlibatan ibu bapa dalam proses pendidikan } \\
\text { amatlah penting bagi membentuk sikap positif } \\
\text { dan konsep kendiri anak terhadap Sains. }\end{array}$ \\
$\begin{array}{l}\text { Ibu bapa membelikan buku-buku rujukan } \\
\text { Sains yang diperlukan dan menyediakan } \\
\text { iklim belajar yang selesa di rumah. }\end{array}$ & $\begin{array}{l}\text { Buku rujukan Sains disediakan supaya murid } \\
\text { dapat mengulang kaji pelajaran dan menyedikan } \\
\text { suasana pembelajaran yang selesa di rumah. }\end{array}$ \\
$\begin{array}{l}\text { Tanggungjawab ibu bapa untuk } \\
\text { menggalakkan anak-anak menyertai } \\
\text { aktiviti dan program yang dianjurkan } \\
\text { oleh sekolah bagi meningkatkan prestasi } \\
\text { akademik dan kemahiran insaniah. }\end{array}$ & $\begin{array}{l}\text { Galakan untuk menyertai aktiviti dan program } \\
\text { yang dianjurkan di sekolah dalam meningkatkan } \\
\text { prestasi akademik dalam subjek Sains dan juga } \\
\text { peningkatan kemahiran insaniah murid. }\end{array}$ \\
\hline
\end{tabular}




\begin{tabular}{|c|c|}
\hline Responden 2 & \\
\hline $\begin{array}{l}\text { Ibu bapa membantu dalam mencari } \\
\text { maklumat dan bahan-bahan sokongan } \\
\text { yang berkaitan dengan Sains melalui } \\
\text { internet dengan mengaplikasikan dalam } \\
\text { pengajaran dan pembelajaran Sains. }\end{array}$ & $\begin{array}{l}\text { Ibu bapa mencari infomasi serta bahan Sains } \\
\text { melalui internet. Dengan menggunakan bahan } \\
\text { sokongan dapatlah untuk menarik minat anak. } \\
\text { Ia akan merangsang perasaan keinginan belajar. }\end{array}$ \\
\hline $\begin{array}{l}\text { Ibu bapa sentiasa memberikan sokongan } \\
\text { moral untuk saya menyertai aktiviti- } \\
\text { aktiviti yang berkaitan dengan Sains di } \\
\text { sekolah. }\end{array}$ & $\begin{array}{l}\text { Galakan dan sokongan moral diberikan agar } \\
\text { dapat menyertai aktiviti Sains yang dianjurkan } \\
\text { oleh pihak sekolah. }\end{array}$ \\
\hline $\begin{array}{l}\text { Penyertaan dan saranan-saranan ibu } \\
\text { bapa membantu dalam memberikan } \\
\text { sumbangan kepada pihak sekolah. }\end{array}$ & $\begin{array}{l}\text { Penyertaan dan saranan-saranan ibu bapa } \\
\text { banyak membantu dalam mendidik anak dalam } \\
\text { subjek Sains. }\end{array}$ \\
\hline Responden 3 & \\
\hline $\begin{array}{l}\text { Pembentukan sahsiah yang mulia agar } \\
\text { dapat mencapai keputusan yang baik } \\
\text { dalam mata pelajaran Sains. }\end{array}$ & $\begin{array}{l}\text { Ibu bapa sentiasa memupuk sikap yang positif } \\
\text { terhadap Sains dan sentiasa merangsang minat } \\
\text { untuk belajar Sains. }\end{array}$ \\
\hline $\begin{array}{l}\text { Penyediaan ruang belajar yang selesa dan } \\
\text { ceria mewujudkan suasana pembelajaran } \\
\text { yang kondusif. }\end{array}$ & $\begin{array}{l}\text { Peka kepada tanggungjawab menyediakan } \\
\text { kemudahan yang sesuai untuk pembelajaran } \\
\text { Sains kepada murid. }\end{array}$ \\
\hline $\begin{array}{l}\text { Perkembangan anak sentiasa } \\
\text { diperhatikan dengan cara berjumpa } \\
\text { dengan guru-guru Sains. }\end{array}$ & $\begin{array}{l}\text { Sentiasa berjumpa dengan guru yang mengajar } \\
\text { Sains untuk mengetahui pencapaian dalam } \\
\text { mata pelajaran ini. }\end{array}$ \\
\hline Responden 4 & \\
\hline $\begin{array}{l}\text { Ibu bapa berperanan dalam membentuk } \\
\text { sikap positif terhadap subjek Sains. }\end{array}$ & $\begin{array}{l}\text { Pembentukan peribadi dapat merangsang murid } \\
\text { untuk belajar mata pelajaran Sains dengan lebih } \\
\text { gigih. }\end{array}$ \\
\hline $\begin{array}{l}\text { Dorongan diberikan untuk menyertai } \\
\text { program yang dianjurkan oleh pihak } \\
\text { sekolah. }\end{array}$ & $\begin{array}{l}\text { Ibu bapa sentiasa memberi sokongan dan } \\
\text { dorongan untuk menyertai aktiviti di sekolah. }\end{array}$ \\
\hline $\begin{array}{l}\text { Seringkali berjumpa dengan guru untuk } \\
\text { mengetahui perkembangan anak. }\end{array}$ & $\begin{array}{l}\text { Berjumpa dengan guru Sains untuk mengetahui } \\
\text { prestasi anak dalam mata pelajaran Sains. }\end{array}$ \\
\hline
\end{tabular}




\section{Responden 5 \\ Ibu bapa berperanan dalam membentuk sikap positif terhadap subjek Sains. \\ Kemudahan yang lengkap disediakan agar dapat memperoleh keputusan yang baik dalam Sains. \\ Responden 6 \\ Pembentukan sahsiah dan sikap positif terhadapa Sains harus diutamakan oleh ibu bapa. \\ Ibu bapa menasihati anak untuk menyertai aktiviti yang dianjurkan oleh pihak sekolah.}

\section{Responden 7}

Sikap positif terhadap Sains dibentuk supaya memperoleh pretasi yang cemerlang.

Ibu bapa memberikan sokongan moral untuk saya menyertai aktiviti yang berkaitan dengan Sains di sekolah.

Ibu bapa bergiat aktif dalam aktiviti yang dianjurkan melalui program Ibu bapa.

\section{Responden 8}

Ruang belajar yang selesa disediakan dan membelikan keperluan asas yang diperlukan.

Galakan dan dorongan yang diberi supaya sentiasa menceburkan diri dalam program di sekolah.

Setiap kali berjumpa dengan guru Sains untuk mengetahui perkembangan dalam Sains.
Penglibatan ibu bapa dalam proses pendidikan amatlah penting bagi membentuk sikap positif terhadap Sains.

Responden ini menyediakan kemudahan yang asas dan bantuan supaya anak mendapat pencapaian yang baik.

Memupuk sikap positif dalam diri murid supaya memperoleh keputusan yang baik. Perkara ini harus diutamakan oleh ibu bapa.

Penyertaan anak dalam aktiviti yang dianjurkan oleh sekolah seringkali diberikan galakan.

Penyemaian sikap positif terhadap mata pelajaran Sains dapat dibentuk agar memperoleh keputusan yang baik.

Galakan oleh ibu bapa yang diberikan agar dapat menyertai aktiviti Sains yang dianjurkan oleh pihak sekolah.

Penglibatan secara aktif dalam aktiviti dan program yang melibatkan ibu bapa.

Suasana pembelajaran yang kondusif dan memenuhi segala keperluan asas dalam pembelajaran Sains di rumah.

Ibu bapa perlu beri galakan dan dorongan yang padu dalam menggalakkan murid untuk menyertai program di sekolah secara aktif.

Perkembangan anak sentiasa diketahui dengan cara berjumpa dengan guru-guru Sains. 


\begin{tabular}{|c|c|}
\hline Responden 9 & \\
\hline $\begin{array}{l}\text { Ibu bapa mendorong sikap murid ke arah } \\
\text { yang positif secara maksimum. }\end{array}$ & $\begin{array}{l}\text { Sikap positif dapat dibentuk dengan sokongan } \\
\text { dan dorongan daripada ibu bapa. }\end{array}$ \\
\hline $\begin{array}{l}\text { Galakan dan dorongan yang diberi } \\
\text { supaya sentiasa menceburkan diri dalam } \\
\text { program di sekolah. }\end{array}$ & $\begin{array}{l}\text { Galakan dan dorongan dalam penyertaan secara } \\
\text { aktif dalam program yang diadakan di sekolah. }\end{array}$ \\
\hline 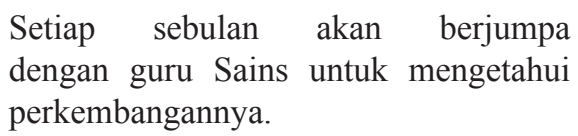 & $\begin{array}{l}\text { Perjumpaan dengan guru Sains agar dapat } \\
\text { mengetahui perkembangan dalam Sains. }\end{array}$ \\
\hline Responden 10 & \\
\hline $\begin{array}{l}\text { Mengajar anak membantu dalam } \\
\text { membuat kerja sekolah yang diberikan } \\
\text { oleh guru Sains. }\end{array}$ & $\begin{array}{l}\text { Responden ini menyatakan bahawa bantuan } \\
\text { akan diberikan dalam menyiapkan kerja sekolah } \\
\text { dan dapat mengembangkan perkembangan } \\
\text { murid. }\end{array}$ \\
\hline $\begin{array}{l}\text { Dorongan akan diberikan agar } \\
\text { memperoleh keputusan yang cemerlang. }\end{array}$ & $\begin{array}{l}\text { Ibu bapa ini memberikan bimbingan dan } \\
\text { tunjuk ajar supaya ini dapat membantunya } \\
\text { memperoleh keputusan yang baik. }\end{array}$ \\
\hline
\end{tabular}

Hasil kajian menunjukkan terdapat enam cara ibu bapa membantu murid dalam mata pelajaran Sains. Cara-caranya ialah pembentukan keperibadian anakanak, penyediaan kemudahan yang lengkap, tunjuk ajar di rumah, galakan kepada anak untuk menyertai aktiviti dan program di sekolah, penyertaan dalam program ibu bapa dan hubungi pihak sekolah untuk mengetahui perkembangan anak di sekolah.

Pengkaji mendapati bahawa kaedah yang popular adalah pembentukan keperibadian anak-anak di rumah membantu murid mempelajari Sains. Seramai tujuh orang responden menyatakan bahawa perlu memberi galakan kepada anak untuk menyertai aktiviti dan program yang dilaksanakan di peringkat sekolah. Selain itu, penyelidik mendapati tiga orang responden menyatakan ruang belajar yang selesa perlu disediakan di rumah. Ibu bapa juga perlu menyediakan kemudahan yang lengkap di rumah seperti Jadual 3.

\section{RUMUSAN}

Sebagai kesimpulannya, hasil interpretasi penyelidik terhadap bahan kajian tentang sikap murid terhadap mata pelajaran Sains di sekolah, cara-cara guru membantu murid dan cara-cara ibu bapa membantu murid dalam mata pelajaran Sains di sekolah, penyelidik mendapati masalah utama yang dihadapi oleh murid di Sekolah Jenis Kebangsaan (Tamil) ialah sikap murid terhadap Sains. Terdapat enam cara yang popular untuk ibu bapa dapat membantu murid tahun lima dalam mata pelajaran Sains di Sekolah Jenis Kebangsaan (Tamil) ialah ibu bapa perlu menghubungi pihak sekolah untuk mengetahui kemajuan anak mereka, menyediakan kemudahan belajar 
Sains di rumah, menyertai program Ibu bapa dan memberi tunjuk ajar kepada anak. Manakala cara yang paling popular yang membantu meningkatkan murid dalam subjek Sains ialah membentuk peribadi dan sahsiah anak, menggalakkan anak untuk menyertai aktiviti atau program sekolah dalam meningkatkan pencapaiannya dalam subjek Sains.

\section{RUJUKAN}

Agranovich, S., \& Assaraf, O, B. (2013). What Makes Children Like Learning Science ? An Examination of the Attitudes of Primary School Students towards Science Lessons. Journal of Education and Learning, 2(1). 55-69.

Ali, M. M., Yager, R. E., Hacieminoglu, E., \& Caliskan, İ. (2013). Changes in Student Attitudes Regarding Science When Taught by Teachers Without Experiences with a Model Professional Development Program. School Scienceand Mathematics, 113(3), 109-119.

Bahagian Pembangunan Kurikulum. (2014). Kurikulum Sepadu Sekolah Rendah. Dokumen Standard Kurikulum dan Pentaksiran Sains tahun 5. Putrajaya: Kementerian Pendidikan Malaysia.

Hacieminoglu, E., Yilmaz-Tuzun, O., \& Ertepinar, H. (2009). Investigating Elementary Students'.

Learning Approach, Motivational Goals and Achievement in Science. Hacettepe University. Journal of Education, 37, 72-83.

Higgs, J. Paterson, M. \& Kinsella, E. A.. (2012). Hermeneutic Analysis: Interpretation and Understandingin Research and Practice. Contemporary Psychotherapy, 4: $1-15$.

Kamisah, O., Zanaton, H. I. \& Lilia, H. (2007). Sikap Terhadap Sains dan Sikap Saintifik di Kalangan Pelajar Sains. Jurnal Pendidikan. 32, 39-60.

Lyons, E. \& Coyle, A. (2007). Analysing Qualitative Date in Psychology: London: SAGE Publications.

Pelan Pembangunan Pendidikan Malaysia 2013-2025. (2013). Putrajaya: Kementerian Pendidikan Malaysia.

Ragin, C. C. (1994). Constructing Social Research. Thousand Ooks. California: Pine Forge Press.

Suppiah, N. (2003). Proses kognitif dalam penulisan esei melalui analisis hermeneutik. Minden: Universiti Sains Malaysia (Tesis Doktor Falsafah yang tidak diterbitkan). Suppiah, N. (2013). Proses Kognisi Dan Afeksi: Kaedah Pedagogi Hermeneutik dan Interpretasi. Tanjong Malim: Penerbit Universiti Pendidikan Sultan Idris.

Suppiah, N. (2014). Gaya Bahasa dan Proses Kognisi: Kaedah Pedagogi Hermeneutik dan Interpretasi. Tanjong Malim: Penerbit Universiti Pendidikan Sultan Idris.

Suppiah, N. (2016). Kaedah Hermeneutik: Kaedah interpretasi teks secara kualitatif.

Tanjong Malim: Penerbit Universiti Pendidikan Sultan Idris.

Talib, O., Luan, W. S., Azhar, S. C. \& Abdullah, N. (2009). Uncovering Malaysian Students Motivation to Learning Science. European Journal of Social Science, 8(2): 266-276. 